\title{
National Center for Research Resources
}

National Cancer Institute

\section{Source}

National Cancer Institute. National Centerfor Research Resources. NCI Thesaurus. Code C20016.

A center within the National Institutes of Health that provides laboratory scientists and clinical researchers with the tools and training they need to understand, detect, treat, and prevent a wide range of diseases. 